\title{
Knowing but not remembering: Adult age differences in recollective experience
}

\author{
TIMO MÄNTYLÄ \\ University of Stockholm, Stockholm, Sweden
}

\begin{abstract}
Age differences in recollective experience were examined in two experiments in which younger and older adults used their self-generated associations as retrieval cues. When recalling an item, subjects indicated whether they consciously remembered its prior occurrence, or merely knew that it was presented previously. The results of both experiments showed that aging selectively impaired retention accompanied by recollective experience, as measured by remember responses, but had no effects in the absence of recollective experience, as measured by know responses. In Experiment 2, a similar pattern of data was obtained for a group of younger adults by increasing the rate of presentation at study. The results also indicated that judgments of recollective experience were related to type of encoding: Subjects who generated detailed associations reported higher levels of remember responses and lower levels of know responses than did subjects who generated fewer detailed associations. The results are discussed in terms of processes related to perceptual familiarity and contextual detail.
\end{abstract}

In recent years, there has been a resurgence of interest in unconscious processes. This reflects a renewed interest in consciousness, which is particularly apparent in research in which the effects of prior experience are measured indirectly rather than explicitly (see Richardson-Klavehn \& Bjork, 1988, and Schacter, 1987, for reviews). These indirect measures, such as word-stem and word-fragment completions, can be contrasted with more traditional direct measures of memory, such as recall and recognition, in which subjects are directed consciously to recollect prior events. Research on amnesics (e.g., Warrington \& Weiskrantz, 1970) and normal young adults (e.g., Jacoby \& Dallas, 1981) has revealed that subjects perform differently on tasks requiring conscious recollection of a previously studied episode than on tasks that measure the effect of prior study episode in an indirect manner.

One central characteristic of this approach is that the presence or absence of conscious experience is inferred on the basis of subjects' performance on different measures of memory. That is, the nature of conscious experience has been studied in terms of implicit and explicit memory tests rather than by measuring recollective experiences directly. However, attempts have also been made to actually study conscious experience without resorting to indirect behavioral measures (e.g., Gardiner, 1988; Tulving, 1985). The point of departure for these studies has been the notion that different patterns of performance can be observed within a memory task that taps the conscious recollection of an event, depending on the subjective experience of the

This research was supported by a grant from the Swedish Council for Research in the Humanities and Social Sciences. I thank Maria Westlander for her assistance in data collection. Correspondence concerning this article should be addressed to T. Mäntylä, Department of Psychology, University of Stockholm, 10691 Stockholm, Sweden. rememberer. According to this approach, conscious awareness of recognition is assumed to reflect two distinct forms of remembering. Namely, an event is recognized or recalled when its occurrence brings to mind some specific experience in which the event was originally encoded. Alternatively, an event is recognized, not because of specific images or experiences, but because of the feelings of familiarity that can be attributed to it. That is, the individual is able to tell that a given item is familiar, but does not remember actually seeing the item, or have a conscious recollection of it.

Tulving (1985) examined recollective experience by using a distinction between remember and know judgments. According to this distinction, word recognition measured by a remember response indicates that recognizing the word brings to mind some conscious recollection of its prior occurrence in the list, such as an association or image it has triggered or something about its appearance. A know response is assumed to indicate that recognizing the word brings nothing to mind other than a feeling of familiarity. That is, the subject is able to tell that a given item has previously been presented, but does not have a recollection of its prior occurrence in the study list. Thus, although the task reflects explicit measures of retention, subjects are instructed to differentiate their retention of the study events into two types of responses.

A series of experiments reported by Gardiner and his colleagues (Gardiner, 1988; Gardiner \& Java, 1990, 1991; Gardiner \& Parkin, 1990) have shown that several variables produce dissociations between remember and know judgments. Variables such as divided attention, levels of processing, and retention interval influenced only recognition accompanied by recollective experience, as measured by remember responses, whereas recognition in the absence of recollective experience, as measured by know 
responses, was not influenced by any of these variables. Furthermore, Gardiner and Parkin (1990, Experiment 2) demonstrated opposite effects of a variable on remember and know responses. Subjects who had studied a list of words and nonwords gave more know responses to nonwords than to words, whereas they gave more remember responses to words than nonwords. These findings are especially intriguing, considering that both response types were based on explicit measures of retention.

Gardiner and his collaborators have suggested that the dissociations between remember and know judgments could be explained in terms of exclusivity between processes underlying these two types of responses. According to this notion (see also Jones, 1980), the processes underlying remember and know judgments are exclusive in the sense that they "have no relation with one another, so that the outcome of one component exerts no influence whatsoever over the other component"' (Gardiner \& Parkin, 1990, p. 582). Gardiner also suggested that remember responses indicate elaborative or conceptually driven processing in an episodic memory system and that know responses indicate data-driven processing, arising in a perceptual representation system that does not include associative or semantic information (Schacter, 1990; Tulving \& Schacter, 1990).

Although the mechanisms underlying judgments of recollective experience are open to debate, Gardiner's conceptualization accords with several contemporary accounts of memory in that it distinguishes between processes dependent on activation or perceptual familiarity and those related to the processing of contextual detail (Atkinson \& Juola, 1974; Gillund \& Shiffrin, 1984; Jacoby \& Dallas, 1981; Johnston, Dark, \& Jacoby, 1985; Mandler, 1980). For example, on the basis of the findings that parallel effects of perceptual variables are observed on recognition memory tasks and on perceptual implicit memory tasks, Jacoby (1983; Jacoby \& Dallas, 1981) argued that recognition memory has two bases: a conceptual component, which is influenced by meaningful processing, and a familiarity component, which is based on perceptual processing.

Concerning the dissociations between remember and know judgments, it is reasonable to argue that memory for contextual detail is a central characteristic of recollective experience. That is, associations between an event and the environmental and cognitive context in which it occurs not only provide a basis for successful retrieval, but also may support recollective experience in episodic remembering. Distinctive contextual details can be useful for distinguishing among instances of the same general theme (Friedman, 1979); remembering a specific contextual detail of an earlier event may serve as an important means by which that particular episode is "remembered" and differentiated from other similar events. Furthermore, remembering contextual details such as spatiotemporal information, thoughts, feelings, and associations of an earlier episode is thought to underlie reality monitoring, the discrimination of facts, and fantasies (Johnson \& Raye, 1981).
Several studies in the aging literature suggest that tasks requiring only activation of preexisting memory representations show minimal age differences, whereas tasks requiring integration of contextual information are more age sensitive (Balota \& Duchek, 1988; Howard, McAndrews, \& Lasaga, 1981; Light, Singh, \& Capps, 1986; see also Hultsch, Masson, \& Small, 1991; Light, 1991). Older adults appear to have more difficulties than younger adults do in remembering the source of the information that they have learned earlier, suggesting that there are age-related differences in memory for contextual detail. For example, elderly people have more trouble than younger adults in remembering whether information has been presented auditorily or visually (Lehman \& Mellinger, 1984; McIntyre \& Craik, 1987), in a male or a female voice (Kausler \& Puckett, 1981), in upper- or lowercase letters (Kausler \& Puckett, 1980), or in a particular color (Park \& Puglisi, 1985). Furthermore, older adults perform worse than younger adults when asked to recall whether a word has been thought or said (Hashtroudi, Johnson, \& Chrosniak, 1989) or generated or read (Mitchel, Hunt, \& Schmitt, 1986), or whether an act has already been performed (Koriat, Ben-Zur, \& Sheffer, 1988).

If we consider that older adults appear to have impaired memory for contextual information, and assume that remembering contextual details is an essential component of recollective experience, it is reasonable to expect age differences in episodic memory performance when retrieval is accompanied by recollective experience, but not necessarily in its absence. Specifically, given the reasoning outlined above, the purpose of this study was to test the hypothesis that aging selectively impairs retention accompanied by recollective experience, as measured by remember responses, but has no effects on retention in the absence of recollective experience, as measured by know responses.

In all the experiments done by Gardiner and his collaborators, the nature of recollective experience was measured in a recognition memory task. In the present study, judgments of recollective experience were based on responses from a cued-recall test in which subjects were cued by associations self-generated during the study phase. Research on young (Mäntylä, 1986; Mäntylä \& Nilsson, 1988) and older adults (Bäckman \& Mäntylä, 1988; Mäntylä \& Bäckman, 1990) has revealed that self-generated retrieval cues are extremely effective retrieval aids under test conditions in which the study-test compatibility is maintained or reinstated at retrieval. A striking demonstration of their efficiency was obtained in a study done by Mäntylä (1986), in which subjects at study generated associations to 600 randomly selected words. At test, the subjects were asked to recall the previously presented items by using their own associations as cues. The subjects' performance at this unexpected test, which took several hours to complete, was surprising in the sense that even if their retrieval seemed to be relatively effortless, more than $90 \%$ of the items were correctly recalled. Thus, examining retrieval under conditions in which retention is based on subjects' own associations, rather than on copy 
cues, may extend our understanding of the processes underlying recollective experience. Furthermore, examining the self-cuing paradigm in relation to the distinction between "remembering" and "knowing" may increase our knowledge about variables determining cue effectiveness.

In Experiment 1 of the present research, a group of younger and older adults were presented with a list of 120 randomly selected words and were instructed to generate one association for each item presented. At a subsequent recall test, the subjects were presented with their own associations as cues and were instructed to recall the previously presented items. For each word recalled, the subjects also indicated whether they remembered it from the study phase, or whether they merely knew that the word was previously presented. In addition, to increase the confidence of recollective judgments, the subjects were told that if they were not able to decide whether they remembered or knew a given response, they should indicate that their judgment was based on guessing.

An additional purpose of Experiment 1 was to examine the relation between type of encoding and judgments of recollective experience. Specifically, if there were agerelated differences in memory for contextual detail, these differences might not only be reflected in the judgments of recollective experience but also on the type of associations generated. Mäntylä and Bäckman (1990) reported a study in which younger and older adults generated associations to a list of words, in which it was found that older adults provided more schematic descriptions of word meanings than did younger adults, who generated relatively distinctive and idiosyncratic descriptions (i.e., older adults described, for example, the word apple with such associations as fruit, or round, whereas younger adults generated associations such as paradise, or computer).

Given these and other related findings (Bruce \& Herman, 1986; Craik \& Simon, 1980; Hess, 1984; Perlmutter, 1979; Rabinowitz, Craik, \& Ackerman, 1982), older adults were expected to generate relatively schematic descriptions of the stimulus words; consequently, when these descriptions were presented as cues at test, they were expected to evoke recollective experiences to a lower extent than were younger adults' more detailed descriptions. Consequently, if judgments of recollective experience were related to type of encoding, (1) older adults' descrip- tions should be more typical than those of younger adults (i.e., a group of older adults should generate more similar properties than should a group of younger adults), and (2) (younger and older) subjects who generated distinctive descriptions should report high levels of remember responses and low levels of know responses, and vice versa.

\section{EXPERIMENT 1}

\section{Method}

Subjects. Sixteen older adults between 65 and 78 years of age and 16 young adults between 20 and 33 years of age participated in the experiment. The older adults all lived at home and were recruited from senior citizen centers in Stockholm. The younger adults were undergraduates at the University of Stockholm. Background information describing the three groups is shown in the upper part of Table 1 . The vocabulary scores are based on a 30 -item multiple-choice synonym test. Subjects rated their health on a 5point scale ranging from $1=$ very poor to $5=$ excellent. One-way analyses of variance (ANOVAs) showed marginal age effects for vocabulary $\left[F(1,30)=2.65, M S_{\mathrm{e}}=11.28, p<.12\right]$ and years of education $\left[F(1,30)=2.32, M S_{\mathrm{c}}=15.13, p<.15\right]$. The health ratings did not differ between the two age groups $(F<1)$.

Materials and Procedure. The stimulus words consisted of 120 randomly selected items, taken from norms for Swedish nouns (Molander, 1984). Homonyms, cohort-specific words, and words that were likely associates of other stimulus words were avoided. Two random orders of presentation were constructed, and each sublist was tape-recorded (using the voice of the experimenter) at the rate of $10 \mathrm{sec}$ per item.

The subjects, who were tested individually, were given verbal and written instructions in which they were asked to generate one association that, according to their experience, constituted a good description of each word presented. Thus, the subjects might have generated associations such as fruit, yellow, monkey food, or Chiquita for the word banana (cf. Mäntylä, 1986). The subjects were also informed of the subsequent recall test on which they were supposed to recall the target words by using their own associations as cues. The subjects wrote down their descriptions in a booklet, with one association on each page of the booklet. The order of presentation was counterbalanced so that the two sublists occurred equally often in both age groups.

After the study phase, the subjects filled out a background questionnaire and were engaged in informal conversations with the experimenter. Following the 15 -min retention interval, during which the pages of the booklets were randomized, the subjects were given their own descriptions as cues, and they were instructed to recall the words to which they had generated the properties by writing down each word on the appropriate page of the booklet. To avoid

Table 1

Subject Characteristics in Experiments 1 and 2

\begin{tabular}{|c|c|c|c|c|c|c|c|c|}
\hline \multirow[b]{2}{*}{ Condition } & \multicolumn{2}{|c|}{$\begin{array}{c}\text { Age } \\
\text { (years) }\end{array}$} & \multicolumn{2}{|c|}{$\begin{array}{c}\text { Vocabulary } \\
\text { Score }\end{array}$} & \multicolumn{2}{|c|}{$\begin{array}{c}\text { Years of } \\
\text { Education }\end{array}$} & \multicolumn{2}{|c|}{$\begin{array}{l}\text { Health } \\
\text { Rating }\end{array}$} \\
\hline & $M$ & $S D$ & $M$ & $S D$ & $M$ & $S D$ & $M$ & $S D$ \\
\hline \multicolumn{9}{|c|}{ Experiment $1(n=16)$} \\
\hline Young & 26.6 & 5.6 & 25.5 & 2.1 & 13.9 & 1.6 & 3.5 & 0.8 \\
\hline Old & 71.8 & 3.9 & 26.7 & 1.9 & 12.5 & 3.2 & 3.6 & 0.6 \\
\hline \multicolumn{9}{|c|}{ Experiment $2(n=16)$} \\
\hline Young-slow & 26.2 & 5.0 & 25.5 & 2.0 & 13.9 & 1.1 & 3.4 & 0.9 \\
\hline Young-fast & 25.3 & 5.1 & 25.4 & 2.7 & 13.8 & 1.5 & 3.6 & 0.9 \\
\hline Old-slow & 70.1 & 2.4 & 27.6 & 2.1 & 11.7 & 2.7 & 3.5 & 0.5 \\
\hline
\end{tabular}


practice and recency effects, descriptions corresponding with the first and last 15 items were excluded from the cued-recall test.

For each word recalled, the subjects were also asked to place the letter " $R$ " by the word to indicate that they remembered it from the list, or a " $\mathrm{K}$ " if they merely knew that the word was in the list. In addition, they were told that if they were not able to decide whether they "remembered" or "knew" a given response, they should write the letter " $G$ " to indicate that their response was based on guessing. To clarify the distinction between remember and know judgments, the subjects were instructed to make remember responses to items that evoked some specific recollection from the learning sequence. Examples given included remembering a word because it evoked a particular association, image, or some other more personal experience. Know responses were to be given for words that subjects felt confident in recalling, but that failed to evoke any specific conscious recollection from the learning sequence. The subjects were also told that the know response was like recognizing someone in the street, but not remembering who the person was (see also, e.g., Gardiner, 1988). Finally, the experimenter asked each subject if he/she had understood the instructions and whether the distinction between remember and know responses was clear. All participants reported having understood the basis on which to make remember, know, and guess responses, respectively. The recall rate was subject-paced, and the test phase took 25-30 min for the young and 30-40 min for the old to complete. After the test, the subjects were given the vocabulary test, which took approximately $10 \mathrm{~min}$ to complete.

\section{Results and Discussion}

The older and younger adults' responses were subjected to three main analyses. First, to examine age-related differences in recollective experience, each subject's recall scores were analyzed as a function of response type. Furthermore, although the primary interest was on correctly recalled items, intrusion errors were analyzed separately for remember, know, and guess responses, respectively. The intrusion error data were expected to provide additional information about the subjects' strategies in making judgments of recollective experience. For example, if subjects did not have access to some type of familiaritybased retrieval information when making know responses (i.e., 'knowing"' was considered to be a form of guessing), the difference between know and guess judgments might be small or nonexistent for intrusion errors.

Second, to examine age-related differences in type of encoding, the older and younger subjects' descriptions from the study session were analyzed in terms of typicality. Finally, to examine the relation between type of encoding and judgments of recollective experience, each subject's measure of encoding typicality was related to the corresponding remember and know scores.

Recollective experience. Except for plural and definite forms, only the responses that were identical to the tar- get word were accepted as correct. In addition, a response was excluded if it was given to a cue that contained parts of the target item (e.g., the response bookstore was excluded if it had been generated as an association to the word book). The percentage of responses excluded was less than $2 \%$ for both groups.

The analyses were based on both relative measures (i.e., for each subject, the numbers of correct remember, know, and guess responses were divided by the total numbers of items recognized) and absolute measures (i.e., the numbers of correct remember, know, and guess responses were divided by the total numbers of items), but because these calculations showed comparable patterns of results, only the findings on absolute measures are reported. The recall performance of the two age groups is summarized in Table 2, separately for remember, know, and guess responses, respectively. What is readily apparent in these data is that the young adults reported a higher level of remember responses than did the older adults, whereas the age difference in the level of know responses is small or nonexistent. Furthermore, as can be seen from Table 2, the guess responses were about $5 \%$ for both age groups.

The overall data were first analyzed in terms of a multivariate analysis of variance (MANOVA), followed by separate ANOVAs on remember, know, and guess responses, respectively. The MANOVA, with age (young vs. old) as an independent variable and remember, know, and guess responses, respectively, as dependent variables, revealed a significant effect of condition [Wilks's $\lambda=.62$, $F(3,28)=5.75, p<.01]$. A separate one-way ANOVA for remember responses showed a significant main effect of age $\left[F(1,30)=13.19, M S_{\mathrm{e}}=0.64, p<.01\right]$. The corresponding ANOVAs for know and guess responses revealed no reliable effects of condition $\left(F_{\mathbf{s}}<1\right)$.

To provide continuity with past research (e.g., Gardiner, 1988; Gardiner \& Parkin, 1990), responses were analyzed with a separate $2 \times 3$ (age $\times$ response type) mixed ANOVA, with response type as a within-subject variable. This analysis revealed main effects of age $\left[F(1,30)=18.14, M S_{\mathrm{e}}=0.23, p<.01\right]$ and response type $\left[F(2,60)=41.82, M S_{\mathrm{e}}=1.14, p<.01\right]$, as well as a significant interaction between these two factors $\left[F(2,60)=7.50, M S_{\mathrm{e}}=0.20, p<.01\right]$; the HuynhFeldt epsilon for an adjusted $F$ test (Huynh \& Feldt, 1976; $\epsilon=.64, p<.01$ ).

Next, the intrusion error data (i.e., the proportions of incorrect responses that were categorized as remember, know, and guess, respectively) were analyzed as functions of age and type of response. As can be seen from the upper portion of Table 3, the two age groups produced

Table 2

Response Probabilities as a Function of Age in Experiment 1

\begin{tabular}{|c|c|c|c|c|c|c|c|}
\hline \multirow[b]{3}{*}{ Condition } & \multicolumn{7}{|c|}{ Response Type } \\
\hline & \multicolumn{2}{|c|}{ Remember } & \multicolumn{2}{|c|}{ Know } & \multicolumn{2}{|c|}{ Guess } & \multirow{2}{*}{$\begin{array}{c}\text { Total } \\
\boldsymbol{M}\end{array}$} \\
\hline & $M$ & $S D$ & $M$ & $S D$ & $M$ & $S D$ & \\
\hline Young & .54 & .22 & .11 & .12 & .05 & .04 & .70 \\
\hline Old & .26 & .21 & .10 & .14 & .05 & .05 & .41 \\
\hline
\end{tabular}


Table 3

Intrusion Errors as a Function of Condition

and Type of Response in Experiments 1 and 2

\begin{tabular}{|c|c|c|c|c|c|c|c|}
\hline \multirow[b]{3}{*}{ Condition } & \multicolumn{7}{|c|}{ Response Type } \\
\hline & \multicolumn{2}{|c|}{ Remember } & \multicolumn{2}{|c|}{ Know } & \multicolumn{2}{|c|}{ Guess } & \multirow{2}{*}{$\begin{array}{c}\text { Total } \\
\boldsymbol{M}\end{array}$} \\
\hline & $M$ & $S D$ & $M$ & $S D$ & $M$ & $S D$ & \\
\hline \multicolumn{8}{|c|}{ Experiment 1} \\
\hline Young & .05 & .04 & .02 & .02 & .10 & .12 & .17 \\
\hline Old & .05 & .05 & .03 & .03 & .09 & .12 & .17 \\
\hline \multicolumn{8}{|c|}{ Experiment 2} \\
\hline Young-slow & .03 & .03 & .03 & .05 & .09 & .10 & .15 \\
\hline Young-fast & .05 & .04 & .05 & .04 & .12 & .08 & .22 \\
\hline Old-slow & .05 & .07 & .04 & .04 & .15 & .09 & .24 \\
\hline
\end{tabular}

comparable levels of intrusion errors (i.e., $17 \%$ for both groups), and the response patterns were similar. Both groups revealed relatively low levels of remember responses, whereas the guess responses were more than twice as frequent. Particularly noteworthy is that only a small proportion of the intrusion errors were categorized as know responses.

The intrusion error data were analyzed with a $2 \times 3$ (age $X$ response type) mixed ANOVA, with response type as a within-subject variable. This analysis yielded only a main effect of response type $\left[F(2,60)=4.82, M S_{\mathrm{e}}=\right.$ $0.03, p<.01]$. A subsequent Newman-Keuls test revealed that the mean of the guess responses was significantly higher than the means of the two other response types $(p<.05)$. The difference between the means of the remember and know responses was not reliable.

Type of encoding. To examine age-related differences in type of encoding, a measure of encoding typicality was calculated. This was obtained by first determining the most typical descriptions for each item (e.g., fruit was the most typical description of the word banana for both age groups) and then calculating the number of items for which each subject had generated the one most typical description. The resulting typicality scores were expressed in proportions by dividing each subject's typicality score by the total number of 90 items ( 15 recency and primacy items were excluded from the total list of 120 items). For example, if a given subject had generated the most typical description for 18 items, the resulting value of typicality had been $18 / 90=.20$.

The results of this analysis revealed that the older adults generated more typical descriptions $(M=.33)$ than did younger adults $(M=.26)$. This difference was only marginally significant $\left[F(1,30)=2.96, M S_{\mathrm{e}}=0.27, p<\right.$ .10], however.

Recollective experience and type of encoding. Each subject's typicality value was related to the corresponding remember and know scores to examine the relation between judgments of recollective experience and type of encoding. If judgments of recollective experience were related to type of encoding, subjects who generated prototypical descriptions should report lower levels of remember responses and higher levels of know responses than did subjects with fewer prototypical descriptions.
A multiple regression analysis with age, typicality, vocabulary, and education, entered in that order, showed that the four predictors accounted for more than $42 \%$ of the variability in the remember scores $[R=.65, F(4,27)=$ $4.98, p<.01]$. However, age $(\beta=-.52, p<.01)$ and typicality $(\beta=-.33, p<.05)$ were the only significant predictors of remember responses, accounting for more than $40 \%$ of the variability in the remember scores, with education $(\beta=.04)$ and vocabulary $(\beta=.13)$ making no significant contributions ( $p$ s $>.45$ ). A corresponding regression analysis on know judgments revealed that typicality was the only significant predictor of know responses, accounting for more than $17 \%$ of the variance $(\beta=.41, p<.05)$, with age $(\beta=-.25, p<.20)$, education $(\beta=-.09)$, and vocabulary $(\beta=.01)$ making no significant contributions.

Separate regression analyses for the two age groups revealed that the typicality scores were highly correlated with older adults' $(r=-.58, p<.01)$, but not with younger adults' $(r=-.11)$ remember responses. A regression analysis on know responses showed a marginally significant correlation with typicality scores for older $(r=.38, p<.14)$ and younger adults $(r=.37, p<$ .16). However, the results of these separate analyses should be interpreted with caution, because the correlations were based on few observations, and the younger subjects' typicality scores represented a relatively narrow range of values.

To summarize, the results of Experiment 1 indicated age-related differences in retrieval accompanied by recollective experience, as measured by remember responses, whereas recall in the absence of recollective experience, as measured by know responses, revealed similar patterns of results for both age groups. Compared with the results from the studies of Gardiner and his collaborators, the levels of know responses of Experiment 1 were relatively low. This may indicate not only that selfgenerated cues are powerful retrieval aids, but also that they are efficient for evoking specific recollections from the learning sequence

One possible reason for the low levels of know responses may be that three different response categories were used in this study. In contrast to past procedures, the present one did not force the subjects to decide be- 
tween a "remember" or a "know" response, but also had "guessing" as a third response alternative if they were not able to decide whether they remembered or knew a given response. Considering that know responses were defined on the basis of absence of recollective experience, a possibility exists that the subjects were particularly conservative when making know judgments.

The relatively low levels of know responses also may reflect the limited use of the entire range of responses by some subjects. Although the response distributions were similar for both age groups, there were 4 younger adults and 5 older adults who made fewer than two know responses (only 1 older adult made fewer than two remember responses). To further examine possible floor effects in the know judgments, an additional group $\times$ type of response ANOVA was carried out by excluding the six lowest know values from both age groups. This analysis replicated the main findings of Experiment 1 in that the younger adults showed a higher level of remember responses $(M=.43)$ than did the older adults $[M=.21$; $\left.F(1,18)=4.23, M S_{\mathrm{e}}=0.19, p<.05\right]$. However, the age effect for know responses was again unreliable $(F<1)$, with younger adults $(M=.19)$ producing the same level of know responses as that for older adults $(M=.20)$.

\section{EXPERIMENT 2}

The results of Experiment 1 revealed age-related differences in recall accompanied by recollective experience, but not in its absence. These findings also indicate that older adults generated more prototypical descriptions of the stimulus words than younger adults did (Mäntylä \& Bäckman, 1990; Perlmutter, 1979). When these schematic descriptions were presented as cues, they evoked recollective experiences to a lower extent than younger adults' did in their more detailed descriptions. That is, older adults at least in part reported lower levels of remember responses because their encoding was less detailed than that of younger adults.

Assuming that age differences in remember responses can be attributed to age-related differences in generality of encoding, a similar pattern of results might be obtained for younger adults by decreasing their resources for detailed encoding. This was accomplished in Experiment 2 by manipulating the rate of presentation at study. Specifically, a group of younger adults heard each item at the rate of $5 \mathrm{sec}$ per item (young-fast condition), whereas the rate of presentation was $10 \mathrm{sec}$ per item for one group of young and older adults (young-slow and old-slow conditions). Thus, younger adults who generated associations under conditions in which the rate of presentation was twice as fast were expected to have fewer resources for extensive conceptual analyses than were subjects who generated associations at a slower pace. The manipulation of presentation rate was expected to reduce the overall recall level, but a more important question in the present context was whether an increased presentation rate would selectively impair younger adults' recollec- tive experience. That is, whether remember responses would decrease as a function of increasing presentation rate, with know responses being relatively insensitive to the manipulation of presentation rate.

\section{Method}

Subjects. Sixteen older adults between 65 and 75 years of age and 32 young adults between 19 and 32 years of age participated voluntarily in the experiment. The older adults all lived at home and were recruited from senior citizen centers in Stockholm. The younger adults were undergraduates at the University of Stockholm. Background information describing the three groups is shown in the lower portion of Table 1 . ANOVAs showed significant differences in vocabulary $\left[F(2,45)=4.50, M S_{\mathrm{e}}=23.40, p<.05\right]$, favoring older adults. Furthermore, the two groups of younger adults reported higher levels of formal education than did older adults $\left[F(2,45)=6.93, M S_{e}=25.35, p<.01\right]$. The health ratings did not differ among the three groups $(F<1)$.

Materials and Procedure. The stimulus words consisted of the 120 nouns used in Experiment 1 . Two random orders of presentation were constructed, and each sublist was tape-recorded at the rates of 5 and $10 \mathrm{sec}$ per item.

The subjects were asked to generate one association that, according to their experience, constituted a good description of each presented word. They were informed of the subsequent recall test in which they were supposed to recall the target words by using their own associations as cues. The subjects wrote down their descriptions in a booklet, with one association on each page of the booklet. The presentation of sublists was counterbalanced so that both lists occurred equally often in each condition. The rate of presentation was $10 \mathrm{sec}$ per item for one group of young and older adults (young-slow and old-slow conditions), whereas an additional group of young adults heard each item at the rate of $5 \mathrm{sec}$ per item (youngfast condition).

Immediately after the study phase, the subjects were given their own descriptions as cues and were instructed to recall the words to which they had generated the properties by writing down each word on the appropriate page of the booklet. As in Experiment 1, the order of presentation was random, and descriptions corresponding with the first and last 15 items were excluded from the cuedrecall test. The instructions for the judgments of recollective experience were the same as the corresponding instructions in Experiment 1 . That is, for each word recalled, the subjects were also asked to place the letter ' $R$ '" by the word to indicate that they remembered it from the list, or a " $K$ " if they merely knew that the word was on the list. In addition, the subjects were told that if they were not able to decide whether they remembered or knew a given response they should write the letter " $G$ " to indicate that their judgment was based on guessing. The recall rate was subject-paced, and the test phase took about $25-30 \mathrm{~min}$ for the young and about 30-40 min for the old to complete. After the test, the subjects were given a background questionnaire and the vocabulary test, which took approximately $15 \mathrm{~min}$ to complete.

\section{Results and Discussion}

As in Experiment 1, correct and incorrect responses were analyzed as a function of response type. Furthermore, to examine the relation between type of encoding and recollective experience, each subject's measures of typicality were related to the corresponding scores of remember and know responses.

Recollective experience. The response distributions were comparable among the three conditions, with 1 young subject in the slow and fast conditions and 2 older subjects making fewer than two know responses. There 
Table 4

Response Probabilities as a Function of Condition in Experiment 2

\begin{tabular}{|c|c|c|c|c|c|c|c|}
\hline \multirow[b]{3}{*}{ Condition } & \multicolumn{7}{|c|}{ Response Type } \\
\hline & \multicolumn{2}{|c|}{ Remember } & \multicolumn{2}{|c|}{ Know } & \multicolumn{2}{|c|}{ Guess } & \multirow{2}{*}{$\begin{array}{c}\text { Total } \\
M\end{array}$} \\
\hline & $M$ & $S D$ & $M$ & $S D$ & $M$ & $S D$ & \\
\hline Young-slow & .43 & .15 & .13 & .11 & .05 & .03 & .61 \\
\hline Young-fast & .28 & .12 & .15 & .13 & .04 & .04 & .47 \\
\hline Old-slow & .24 & .21 & .19 & .18 & .04 & .03 & .47 \\
\hline
\end{tabular}

were no subjects who made fewer than two remember responses. The percentage of items to which subjects did not generate associations was less than $3 \%$ in the youngand old-slow conditions and $4 \%$ in the young-fast condition $(F<1)$. These items were excluded from the subsequent recall test.

As in Experiment 1, both relative and absolute measures were calculated, but because these analyses revealed comparable patterns of results, only the results on absolute proportions are reported. The recall performance of the three conditions is summarized in Table 4 , separately for remember, know, and guess responses, respectively. These data indicate that the level of correct remember responses is highest in the young-slow condition, whereas the difference between the old-slow and young-fast conditions is small or nonexistent. Furthermore, as can be seen from Table 4, the older adults' know responses were slightly, but not significantly, higher than those of the two groups of younger adults. Finally, the proportion of guess responses was less than $5 \%$, with small differences among the three conditions.

The overall data were first analyzed with a MANOVA, followed by ANOVAs on remember, know, and guess responses, respectively. The MANOVA, with condition (young-slow, young-fast, and old-slow) as an independent variable and remember, know, and guess responses, respectively, as dependent variables, revealed a marginal effect of condition [Wilks's $\lambda=.76, F(6,86)=2.02$, $p<.07]$.

A separate one-way ANOVA for remember responses revealed a significant effect of condition $[F(2,45)=5.86$, $\left.M S_{\mathrm{e}}=0.16, p<.01\right]$. A subsequent Newman-Keuls test showed that the mean of the young-slow condition was significantly higher than the means of the two other conditions $(p<.05)$. The difference between the means of the young-fast and old-slow conditions was not reliable. The corresponding one-way ANOVAs for know and guess responses revealed no reliable effects $(F \mathbf{s}<1)$. Because age-related differences were observed in vocabulary scores and level of education, the data were reanalyzed by means of separate analyses of covariance (ANCOVAs), with the two background characteristics as regressors. However, the ANCOVAs yielded the same results as did the ANOVAs summarized above.

The intrusion error data, which are summarized in the lower portion of Table 3 , were analyzed with a $3 \times 3$ (condition $\times$ response type) mixed ANOVA, with response type as a within-subject variable. This analysis yielded only a main effect of response type $[F(2,90)=25.36$,
$\left.M S_{\mathrm{e}}=0.10, p<.01\right]$. As in Experiment 1, the mean of the guess responses was significantly higher than the means of the two other response types $(p<.05)$. The difference between the means of the remember and know responses was nonreliable.

Type of encoding and recollective experience. Typicality of encoding was determined by using the same procedure as in Experiment 1. The results of this analysis revealed that the descriptions generated by subjects in the young-slow condition were less typical $(M=.20)$ than those in the old-slow $(M=.31)$ and young-fast $(M=$ .29) conditions $\left[F(2,45)=4.56, M S_{\mathrm{e}}=0.06, p<.02\right]$. The difference between the means of the old-slow and young-fast conditions was not reliable.

To examine the relation between judgments of recollective experience and type of encoding, each subject's typicality value was related to the corresponding remember and know scores. A regression analysis with age, typicality, vocabulary, and education showed that the four predictors accounted for more than $31 \%$ of the variability in the remember scores $[R=.57, F(4,43)=4.99, p<$ $.01]$. Of these variables, typicality was the only significant predictor of remember responses $(\beta=-.43, p<$ $.01)$, with age revealing a marginally significant effect $(\beta=-.26, p<.10)$, whereas education $(\beta=.10)$ and vocabulary $(\beta=.17)$ made no significant contributions ( $p s>.25$ ). A corresponding analysis on know responses revealed that the four predictors accounted for more than $23 \%$ of the variability in the know scores $[R=.48$, $F(4,43)=3.29, p<.02]$. Again, typicality was the only significant predictor $(\beta=.41, p<.01)$, with age $(\beta=$ $.04)$, vocabulary $(\beta=.05)$, and education $(\beta=-.13)$ making no significant contributions ( $p s>.40$ ).

Separate regression analyses for each condition revealed a significant correlation between typicality and remember scores in the young-slow condition $(r=-.56, p<$ $.03)$ and a marginally significant correlation in the oldslow condition $(r=-.45, p<.07)$. The corresponding value for the young-fast condition was not reliable. Furthermore, older adults revealed a highly significant correlation for the know responses $(r=.62, p<.01)$, whereas the corresponding value for the young-fast condition was marginally significant $(r=.44, p<.08)$ and nonreliable for the young-slow condition $(r=.12)$.

To summarize, the results of Experiment 2 replicated the findings of Experiment 1 and suggest that there are age-related differences in remember, but not in know, judgments. The proportions of know responses were higher than the corresponding values in Experiment 1, 
with older adults' know responses being clearly above floor and nearly five times higher than the corresponding guess responses. Furthermore, as in Experiment 1, the results indicated that the magnitude of recollective experience was related to the type of encoding, so that the subjects who generated distinctive descriptions at study reported higher levels of remember responses than did those who generated relatively typical descriptions.

\section{GENERAL DISCUSSION}

Based on past research showing dissociations between remember and know judgments (Gardiner, 1988; Gardiner \& Java, 1990, 1991; Gardiner \& Parkin, 1990), the main objective of this study was to test the hypothesis that aging selectively impairs retention accompanied by recollective experience but has no effects on retention in the absence of recollective experience. In addition, presentation rate was varied for two groups of young adults, the hypothesis being that a faster presentation rate would decrease the level of remember responses, but not that of know responses.

With respect to age-related differences in recollective experience, younger adults showed a higher level of overall recall than did older adults in both experiments, but the difference between the two age groups was attributed to differences in remember, rather than know, responses. The results also showed that the effect of presentation rate was similar to that of age. In fact, the subjects in the young-fast condition revealed a pattern of results that was practically identical to the older subjects' performance under conditions in which the study time was twice as long. Although the manipulation of presentation rate clearly affected the level of remember responses, the know responses were at the same level in both conditions.

The results of this study also suggested that there are age-related differences in type of encoding and that these differences were related to the magnitude of recollective experience. Taken together, the results of the two experiments showed that younger adults' descriptions were less typical than older adults' descriptions in the corresponding condition. Furthermore, the results showed that an increased presentation rate increased the typicality of younger adults' descriptions and revealed a similar pattern of data as that for older adults under conditions in which the rate of presentation was twice as long.

It should be pointed out that although several studies show a lack of age effects on the nature of word associations (Burke \& Peters, 1986; Howard, 1980; Lovelace \& Cooley, 1982), the results of the present study as well as those of Mäntylä and Bäckman (1990) are not inconsistent with these findings. Typically, the free-association data fail to show age-related differences in encoding variability under conditions in which subjects are instructed to respond as quickly as possible with the first word that comes to mind (Clark, 1970). Instead, the task used here was different from the free-association task, in that subjects were not forced to respond with the first word that came to mind, but rather were required to generate associations that, according to their experience, constituted a good description of each stimulus word presented. However, as the results of Experiment 2 indicate, when the rate of presentation was reduced in the fast condition, the typicality of younger adults' descriptions also increased.

The results of Experiment 2 are similar to the pattern of data Gardiner and Parkin (1990) found when they used a divided-attention manipulation. In their study, subjects studied words under an undivided-attention condition, or under one of the two divided-attention conditions. The subjects' attention was divided by using a tone-monitoring task (Parkin \& Russo, 1990), and the difference between the two tasks was that in the second task the tones occurred at twice the rate used in the first condition. The relative proportions of remember responses in their study were approximately $70 \%, 65 \%$, and $55 \%$ in the undividedand the two divided-attention conditions, respectively, whereas the proportions of know responses remained at the same level in all three conditions.

If we consider the similarities between the results of the young-fast and old-slow conditions, a possibility exists that reduced attentional capacity may underlie the observed age differences in judgments of recollective experience. According to this view (Craik \& Byrd, 1982; Hess, 1984; Mäntylä \& Bäckman, 1992; Rabinowitz et al., 1982), older adults rely primarily on processes that place minimal demands on cognitive resources, and they therefore pay increasing attention to schematic information at the expense of distinctive or idiosyncratic detail information (but see also Light, 1991; Park, Puglisi, Smith, \& Dudley, 1987; Puglisi, Park, Smith, \& Dudley, 1988). Although the present study was not explicitly designed to test this notion, its results indicate that the older adults, as well as the younger adults in the fastpresentation condition, focused their attention on relatively schematic properties of the stimulus information, rather than becoming involved in more elaborative analyses. As a consequence of general encoding, recollective experience was to a lesser extent attributed to "remembering" specific details of the previously encoded target information.

As a support for this notion, Mäntylä and Bäckman (1992) have reported a study in which younger and older adults viewed objects in a real-world setting (i.e., an office room). The stimulus objects were familiar objects that were either consistent (e.g., a telephone) or inconsistent (e.g., a mixer) with expectations. Immediate and delayed recognition tests on item information (i.e., distractors were defined by their semantic identity) revealed that younger and older adults recognized unexpected items better than expected items, indicating that both age groups detected inconsistencies in the experimental setting. However, when a more detailed "remembering" was required by requesting recognition of token information (i.e., distractors were defined by their physical appearance), the younger adults showed significantly better memory for details than did the older adults. Furthermore, under divided at- 
tention, the young adults revealed a similar pattern of results as that for the elderly adults under full attention, suggesting capacity-related differences in memory for detail information.

Although the present study supports the notion that different mechanisms may underlie remember and know judgments, there may be substantial variability in how different individuals interpret the distinction between knowing and remembering. In other words, the subjects may have interpreted the distinction between remember and know responses differently and/or have made different decisions about how much contextual detail was needed for "remembering" and how much familiarity or perceptual fluency was required to meet the "knowing" criterion. Furthermore, an important issue for future research done with direct behavioral measures is to examine factors underlying both inter- and intraindividual variability of recollective judgments. That is, there may not only be variability in the manner in which different individuals categorize their recollective experiences, but also in how a given individual categorizes the same target event in different retrieval conditions; certain contextual features may be sufficient for distinguishing a particular episode from other similar episodes, but this information may be insufficient for "remembering" that event on another occasion.

It might be argued that the level of remember responses, in contrast with know responses, decreased in the present study because the two response types correspond to different levels of subjective confidence or trace strength (Gardiner \& Java, 1990, 1991; Gardiner \& Parkin, 1990). That is, age effects on remember responses were observed here because the older adults were less confident than the younger adults when making recollective judgments, resulting in lower levels of remember responses. Consequently, the levels of know and guess responses should have increased if subjects were less confident in their judgments. However, this study as well as relevant past research (Gardiner, 1988; Gardiner \& Java, 1990, 1991; Gardiner \& Parkin, 1990) has shown that know responses remain invariant across manipulations that reduce the level of remember responses. It should also be noted that the levels of guess responses were not affected by the manipulations of age or presentation rate in this study.

Furthermore, the results on the intrusion error data revealed low levels of remember and know responses, but relatively high levels of guess responses in both experiments. The fact that only a small proportion of intrusion errors was categorized as remember responses may indicate that both the younger and the older adults based their remember judgments on some specific recollections from the learning sequence. Furthermore, the finding that the proportions of know responses were significantly lower than those of guess responses for incorrect responses may indicate that the know judgments were based on retrieval information that was qualitatively different from that underlying guessing. That is, the difference between know and guess judgments should have been marginal for in- trusion errors, if subjects did not have access to some type of familiarity-based retrieval information when making know responses.

In summary, the present study accords with a growing body of research that suggests small or nonexistent age differences in processes relying on activation of preexisting knowledge representations, but impaired processing of contextual detail in old age. The present findings extend past research and indicate that aging as well as the manipulation of presentation rate impair retention accompanied by recollective experience, whereas recall in the absence of conscious recollection is not affected by these manipulations. These findings provide further evidence for the notion that explicit memory involves two measurable states of conscious awareness, and that these entities reflect qualitatively different components of remembering.

\section{REFERENCES}

Atrinson, R. C., \& Juola, J. F. (1974). Search and decision processes in recognition memory. In D. H. Krantz, R. C. Atkinson, R. D. Luce, \& P. Suppes (Eds.), Contemporary developments in mathematical psychology: Vol. 1. Learning, memory and thinking (pp. 243-293). San Francisco: W. H. Freeman.

BäCKMAN, L., \& MäNTYLÄ, T. (1988). Effectiveness of self-generated cues in younger and older adults: The role of retention interval. In ternational Journal of Aging \& Human Development, 26, 241-248.

Balota, D. A., \& DucheK, J. M. (1988). Age-related differences in lexical access, spreading activation, and simple pronunciation. Psychology \& Aging, 3, 84-93.

Bruce, P. R., Herman, J. F. (1986). Adult age differences in spatial memory: Effects of distinctiveness and repeated experience. Journal of Gerontology, 41, 774-777.

Burke, D. M., \& Peters, L. (1986). Word associations in old age: Evidence for consistency in semantic encoding during adulthood. Psychology \& Aging, 4, 283-292.

Clark, H. H. (1970). Word associations and linguistic theory. In J. Lyons (Ed.), New horizons in linguistics (pp. 271-286). Baltimore: Penguin Books.

Craik, F. I. M., \& Byrd, M. (1982). Aging and cognitive deficits: The role of attentional resources. In F. I. M. Craik \& S. E. Trehub (Eds.), Aging and cognitive processes (pp. 191-211). New York: Plenum.

Craik, F. I. M., \& Simon, E. (1980). Age differences in memory: The roles of attention and depth of processing. In L. W. Poon, J. L. Fozard, L. S. Cermak, D. Arenberg, \& L. W. Thompson (Eds.), New directions in memory and aging (pp. 95-112). Hillsdale, NJ: Erlbaum.

Friedman, A. (1979). Framing pictures: The role of knowledge in automatized encoding and memory for gist. Journal of Experimental Psychology: General, 108, 316-355.

GARDINER, J. M. (1988). Functional aspects of recollective experience. Memory \& Cognition, 16, 309-313.

GARDINER, J. M., \& JAVA, R. I. (1990). Recollective experience in word and nonword recognition. Memory \& Cognition, 18, 23-30.

GARDINER, J. M. . \& JAVA, R. I. (1991). Forgetting in recognition memory with and without recollective experience. Memory \& Cognition, 19, 617-623.

Gardiner, J. M., \& Parkin, A. J. (1990). Attention and recollective experience in recognition memory. Memory \& Cognition, 18, 579-583.

Gillund, G., \& Shiffrin, R. M. (1984). A retrieval model for both recognition and recall. Psychological Review, 91, 1-67.

Hashtroudi, S., Johnson, M. K., \& Chrosniak, L. D. (1989). Aging and source monitoring. Psychology \& Aging, 5, 106-112.

Hess, T. M. (1984). Effects of semantically related and unrelated contexts on recognition memory of different-aged adults. Journal of Gerontology, 34, 444-451.

HowaRD, D. V. (1980). Category norms: A comparison of the Battig 
and Montague (1969) norms with the responses of adults between the ages of 20 and 80. Journal of Gerontology, 35, 225-231.

Howard, D. V., McAndrews, M. P., \& LASAGa, M. I. (1981). Semantic priming of lexical decisions in young and old adults. Journal of Gerontology, 36, 707-714.

Hultsch, D. F., Masson, M. E., \& SMall, B. (1991). Adult age differences in direct and indirect tests of memory. Journal of Gerontology: Psychological Sciences, 46, 22-30.

HUYNH, H., \& FELDT, L. S. (1976). Estimations of the box correction for degrees of freedom from sample data in the randomized block and split plot designs. Journal of Educational Psychology, 1, 69-82.

JACOBY, L. L. (1983). Remembering the data: Analyzing interactive processes in reading. Journal of Verbal Learning \& Verbal Behavior, $22,485-508$.

JACOBY, L. L., \& Dallas, M. (1981). On the relationship between autobiographical memory and perceptual learning. Joumal of Experimental Psychology: General, 110, 306-340.

JoHNSON, M. K., \& RAYE, C. L. (1981). Reality monitoring. Psychological Review, 88, 67-85

Johnston, W. A., DARK, V. J., \& JACOBY, L. L. (1985). Perceptual fluency and recognition judgments. Journal of Experimental Psychology: Learning, Memory, \& Cognition, 11, 3-11.

JONES, G. V. (1980). Independence and exclusivity among psycholog ical processes: Implications for the structure of recall. Psychological Review, 87, 252-271.

Kausler, D. H., Puckett, J. M. (1980). Adult age differences in recognition memory for a nonsemantic attribute. Experimental Aging Research, 6, 349-355.

Kausler, D. H., \& Puckett, J. M. (1981). Adult age differences in memory for sex of voice. Journal of Gerontology, 36, 44-50.

Koriat, A., Ben-Zur, H., \& Sheffer, D. (1988). Telling the same story twice: Output monitoring and age. Journal of Memory \& Language, 27, 23-39.

Lehman, E. B., \& Melunger, J. C. (1984). Effects of aging on memory for presentation modality. Developmental Psychology, 20, 1210-1217.

Light, L. L. (1991). Memory and aging: Four hypotheses in search of data. Annual Review of Psychology, 42, 333-376

Light, L. L., SINGH, A., \& CAPPS, J. L. (1986). Dissociation in memory and awareness in young and old adults. Journal of Clinical Neuropsychology, 8, 62.

Lovelace, E. A., \& COOLEY, S. (1982). Free associations of older adults to single words and conceptually related word triads. Joumal of Gerontology, 37, 432-437.

MANDLER, G. (1980). Recognizing: The judgment of previous occurence. Psychological Review, 87, 252-271.

MäNTYLÄ, T. (1986). Optimizing cue effectiveness: Recall of 500 and 600 incidentally learned words. Journal of Experimental Psychology: Learning, Memory, \& Cognition, 12, 66-71.

MäNTYLÄ, T., \& BäCKMAN, L. (1990). Encoding variability and agerelated retrieval failures. Psychology \& Aging, 5, 545-550.
MäNTYLÄ, T., \& BäCKMAN, L. (1992). Aging and memory for expected and unexpected objects in real-world settings. Journal of Experimental Psychology: Learning, Memory, \& Cognition, 18, 1298-1309.

MäNTYLä, T., \& Nilsson, L.-G. (1988). Cue distinctiveness and forgetting: Effectiveness of self-generated cues in delayed recall. Journal of Experimental Psychology: Learning, Memory, \& Cognition. 14, 502-509.

MCINTYRe, J. S., \& Craik, F. I. M. (1987). Age differences in memory for item and source information. Canadian Journal of Psychology, 41, 175-192.

Mitchel, D. B., Hunt, R. R., \& Schmitt, F. A. (1986). The generation effect and reality monitoring: Evidence from dementia and normal aging. Joumal of Gerontology, 41, 79-84.

Molander, B. (1984). Imagery, visual and tactual dimensions of imagery and meaningfulness: Swedish norms for 858 nouns (Psychological Report No. 178). Umeá, Sweden: University of Umeå.

Park, D. C., \& Puglisi, J. T. (1985). Older adults' memory for the color of pictures and words. Journal of Gerontology, 40, 198-204.

Park, D. C., Puglisı, J. T., Smith, A. D., \&udley, W. N. (1987). Cue utilization and encoding specificity in picture recognition by older adults. Journal of Gerontology, 37, 330-335.

Parkin, A. J., \& Russo, R. (1990). Implicit and effortful processing and the automatic-effortful distinction. European Journal of Cognitive Psychology, 2, 71-80.

Perlmutter, M. (1979). Age differences in adults' free recall, cued recall, and recognition. Journal of Gerontology, 34, 533-539.

Puglisi, J. T., Park, D. C., Smith, A. D., \& Dudley, W. N. (1988). Age differences in encoding specificity. Journal of Gerontology, 43, 145-150.

Rabinowitz, J. C., Craik, F. I. M., \& Ackerman, B. P. (1982). A processing resources account of age differences in recall. Canadian Journal of Psychology, 36, 325-344.

Richardson-KlaVehn, A., \& BJoRK, R. A. (1988). Measures of memory. Annual Review of Psychology, 39, 475-543.

SCHACTER, D. (1987). Implicit memory: History and current status. Journal of Experimental Psychology: Learning, Memory, \& Cognition, 13, 501-518.

SChacter, D. L. (1990). Perceptual representation systems and implicit memory. In A. Diamond (Ed.), The development and neural bases of higher cortical functions (Annals of the New York Academy of Sciences, Vol. 608, pp. 543-571). New York: New York Academy of Sciences.

Tulving, E. (1985). Memory and consciousness. Canadian Journal of Psychology, 26, 1-12.

Tulving, E., \& SChacter, D. L. (1990). Priming and human memory systems. Science, 247, 301-306.

WARRINGTON, E. K., \& WEISKRANTZ, L. (1970). The amnesic syndrome: Consolidation or retrieval? Nature, 228, 628-630.

(Manuscript received February 3, 1992; revision accepted for publication September 21, 1992.) 